\title{
Rats, Mice and Humans
}

\author{
Pauline Delahaye \\ Université Paris Sorbonne (Paris 4)-EA 4509
}

Received: January 2021 Accepted: March 2021

\begin{abstract}
This paper will introduce the results of a study conducted in 2019 about how humans perceive species they have to live with, despite not wanting to do so-liminal species-, specifically rats and mice. The results presented here are part of a wider study about rats and mice in cities, their relationship with humans, the nuisances they generate as well as the various and important roles they play in the urban ecosystem, introduced at the Gatherings in Blosemiotics 2020.
\end{abstract}

The study originally focused solely on rats, which are in a difficult societal context in France, especially in Paris: due to heat waves, planned works and floods, rats are becoming more and more present on the surface, instead of being invisible underground as they used to be. However, some of the results suggest that a significant number of participants are not completely positive about being able to distinguish between a rat and a mouse. In order to present a more precise and detailed overview, it was decided to study the difference not only between the cohabitation issues humans may have with actual rats and/or mice, but also between the semiotic relationships that humans have with the symbolic rat and symbolic mouse. As such, this paper will present the results for both species, with their similarities and divergences.

It shows that a significant part of nuisances and cohabitation issues are more "believed" than factual. The paper focuses on how the cultural and emotional backgrounds of participants influence their semiotic relationship with these species, and how the perceived nuisances, threats or issues can vary according to these parameters.

This study aims to develop a better understanding of the different elements that play a part in issues of cohabitation between humans-especially urban humans-and liminal species-especially rodents. It will show how some of the nuisances can be addressed, not by coercive methods on the actual animals, such as extermination, repellents or removal, but through semiotic work and education on the symbolic animal, its related myths, superstitions, fears and phobias.

Keywords: rodents; liminal species; urbanism; symbol; emotions; zoosemiotics

\section{INTRODUCTION}

This study was conducted from July to December 2019 It intended to map emotional and symbolic relationships between humans living in Paris and liminal species (Donaldson, Kymlicka 2011) living with them, especially rats. For practical reasons, explained in section "Issues of the study", mice had to be included, but rats remain the core of the study as they carry very old and strong symbolism in cities.
This study was conducted through an online survey (gathering 214 participants) with closed-ended questions, in order to obtain answers easy to compare (see "Methods" section). Four participants then agreed to be interviewed in a more qualitative way. The study introduced here is still incomplete. Other parts were scheduled for 2020 but could not be conducted for pandemic reasons. An overview of them is available in "Further research" section. 


\section{GOALS}

This study has four goals:

1. Compare the real nuisances, which can be measured and documented, with perceived nuisances (on the emotional level) and assumed nuisances (on the symbolical level).

2. Understand how emotional perceptions of a species can influence perceived nuisances.

3. Understand how assumed nuisances were constructed from our symbolical perceptions.

4. Understand what the real nuisances were.

\section{METHODS}

\section{SURVEY}

The first part of the study, running from July to September 2019, was an online self-administered standardized survey with a limited set of possible answers and with only one participation per person possible-a methodology adapted to small samples (Groves 2009). Data about gender, age, area of living and whether they had an occupation affected by liminal species were collected for all participants. As this subject is not very appealing, and the survey was on a voluntary basis, the sample size is small, and some parts of the population were not represented strictly equally-for example, there were slightly more women than men, and the class age repartition is not the same as the general population, especially due to the fact that an online survey was not much accessible to seniors. I made a sample adjustment in order to avoid an obvious sampling error and no significant difference appears between raw and adjusted data, except for a very particular age class and a special category of pet owners-these points of interest are treated in the last two parts of the "Outcomes" section. As a consequence, in this paper I decided to present the figures from the data in the raw sample, except when it is specified otherwise. All the questions of the survey, and their answers, are presented in this paper. The number of participants is 214 .

\section{INTERVIEW}

The second part of the study, running from October to December 2019, was interviews with four participants of the survey who have an occupation impacted by rodents-a pub owner, a barmaid, a cook and a car insurance employee. These qualitative interviews could not be recorded, as the participants were afraid that themselves or their workplaces could be identified, but all my notes were double-checked with them at the end of each interview.

\section{DATA MANAGEMENT}

The online survey did not ask for identifying information, except for an email address some participants could leave in case they had an occupation impacted by rodents and they agreed to be interviewed in the second part of the study.

No other identifying information was collected about these participants during the second part of the study.

\section{CONTEXT OF THE STUDY}

This study takes place in the context of a difficult relationship between rats and people in Paris caused by several natural and urban managemental reasons:

Heat waves: heat waves had become more and more frequent in the last few years, with a particular severe event at the beginning of this study, in July 2019, with $42.6{ }^{\circ} \mathrm{C}$ recorded in Paris (see French Meteorological Archives in references). Similar events occurred in 2018, 2017 and 2015 summers. These heat waves created problems with trash management, attracting rodents, and forced people to delay their activities to evenings and nights, making nocturnal animals like rats more frequently seen.

Floods: Parisians are used to the occasional rise in the Seine's water levels, but floods became more frequent in the last few years, with a particular event in June 2016 (6.10 m) and an important but less serious event in January $2018(5.90 \mathrm{~m})^{2}$. During every occurrence of the Seine flood, rats-and mice-flee their natural nesting areas underground and become more visible and numerous in the city (for illustration, see The Telegraph video archives in references concerning the 2018 flood).

Public works: Paris has one of the most complex and oldest systems of sewers, electricity and gas routing, subways, basements, catacombs and natural cavities. The maintenance and expansion of this system are creating a lot of disturbances for urban rodents as most of these happen in their natural habitat. A more visible and important presence of rats around areas of public works has been reported, without any way to actually quantify it for the moment. But Benoît Pisanu, from the National Museum of Natural History of Paris, explained in an interview (in French, see references) that there was no reason to think that the rat population is growing: planned works just make them more visible, more frequent.

These various reasons also created cohabitation issues with other liminal species, such as cockroaches, seaguIls, crows, etc. but this is not addressed in the present study. For information, Figure 1 shows the percentage of participants attributing the status of "Pest Species" to different liminal species living in Paris.

\footnotetext{
1 During this heat wave, the situation became so visible that the mayor of the $17^{\text {th }}$ district of Paris implemented a website to report the presence of rats: http://signalerunrat.paris/

2 Depending on the time of the year, the river norm is between $1 \mathrm{~m}$ and $2 \mathrm{~m}$. The worst flood historically measured with precision was in 1910 (8.62 m).
} 
As cohabitation issues gain more and more importance, even in political circles, I thought it was time to understand where precisely these issues were: were nuisances factual and documented? Were they rather psychological nuisances? Were there any actual nuisances at all, or just symbolic ones? What is the semiosis used to talk about, think about and interact with these species? kinds of animals are making perception more difficult: they are both nocturnal animals, moving quickly, usually seen in a "surprise" situation. Their semiosis was a very instinctive one and can differ with each constructed discourse they are associated with, when properly asked. To clarify this situation, a metacognition part was scheduled-do people really know what

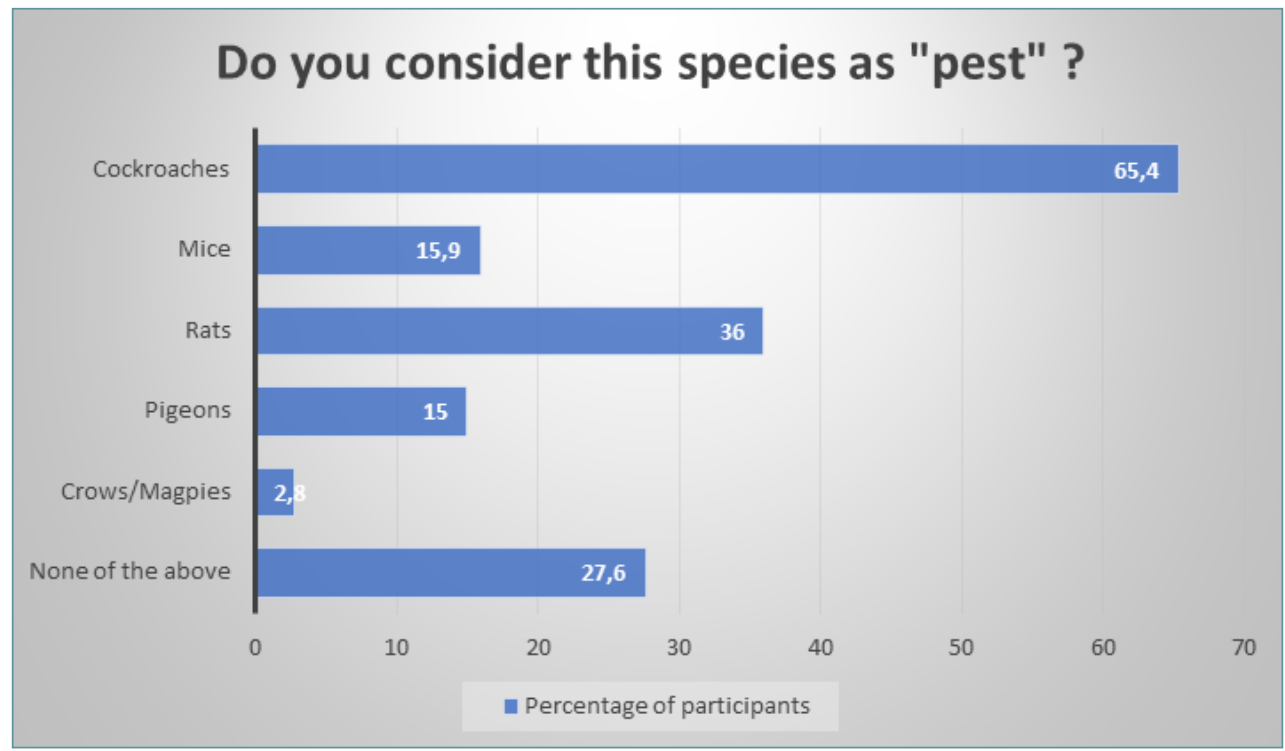

Figure 1: Percentage of participants considering proposed species as "pest".

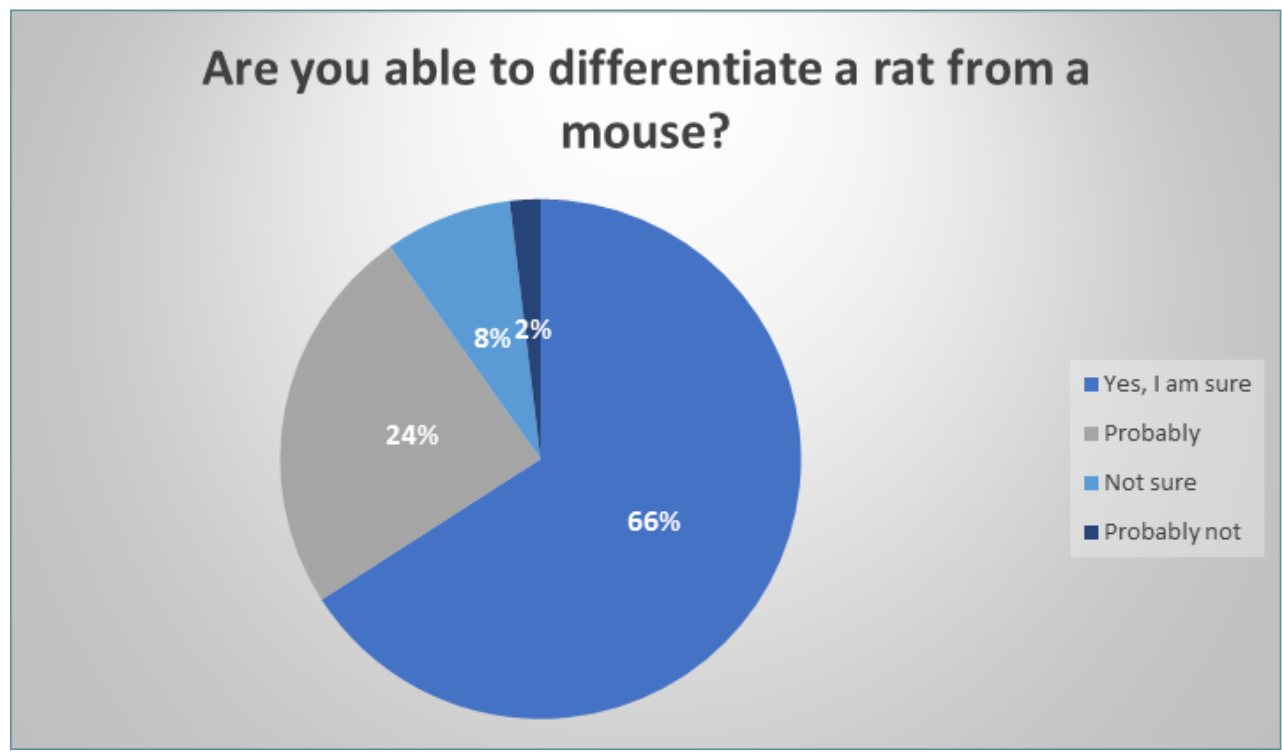

Figure 2: Percentage of participants able to tell the difference between a rat and a mouse

\section{ISSUES OF THE STUDY}

\section{CONFUSION BETWEEN SPECIES AND \\ LACK OF METACOGNITIVE DATA}

The first issue in this study is the probable confusion between rats and mice on the side of the participants. Figure 2 shows that only $65.9 \%$ are sure to be able to tell the difference between one and another. Even more, the actual situations where participants can see these they think they know?-but cannot take place due to the 2020 pandemic situation (see "Further research" section for more details).

This issue is problematic mainly because the emotional perceptions of these two species are quite different, as shown in Figure 3. The detailed symbolical perception, as in Figure 4, shows that while some aspects of the participants' points of view on these two species are common, some are extremely different-like "Carrier 


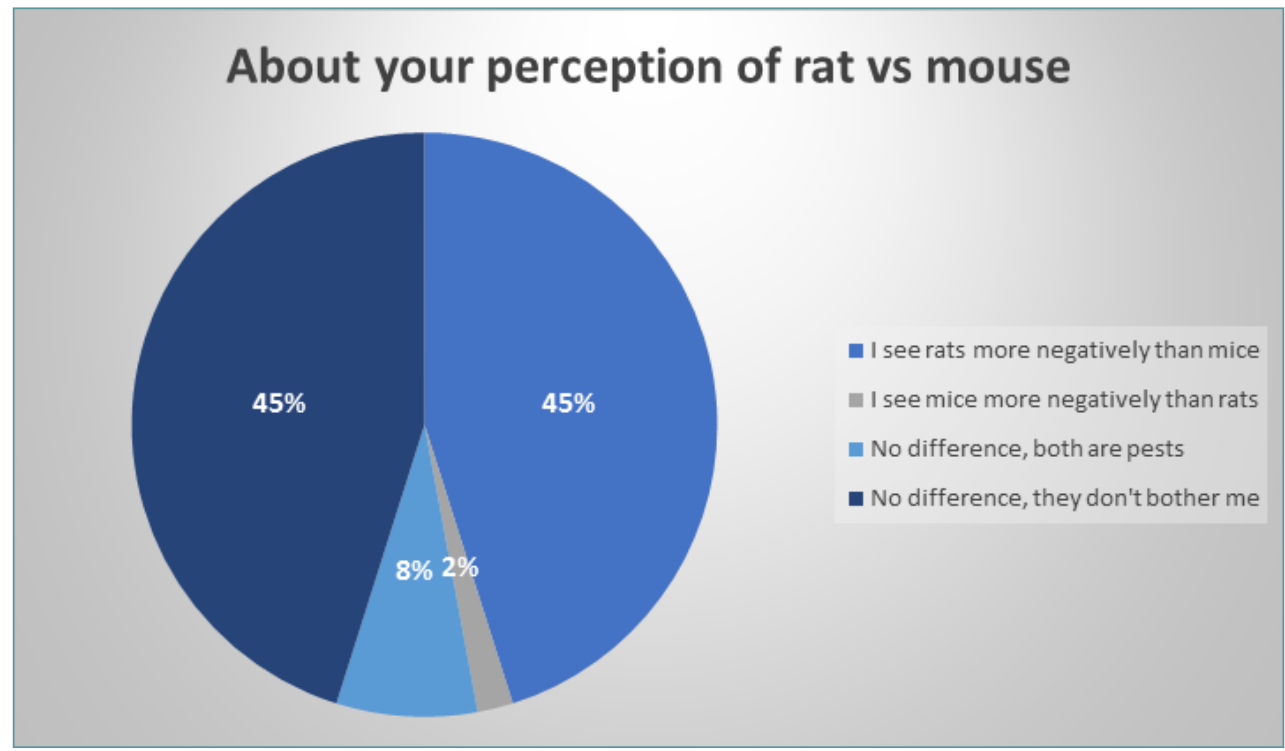

Figure 3: Participants' perception of rats versus mice.

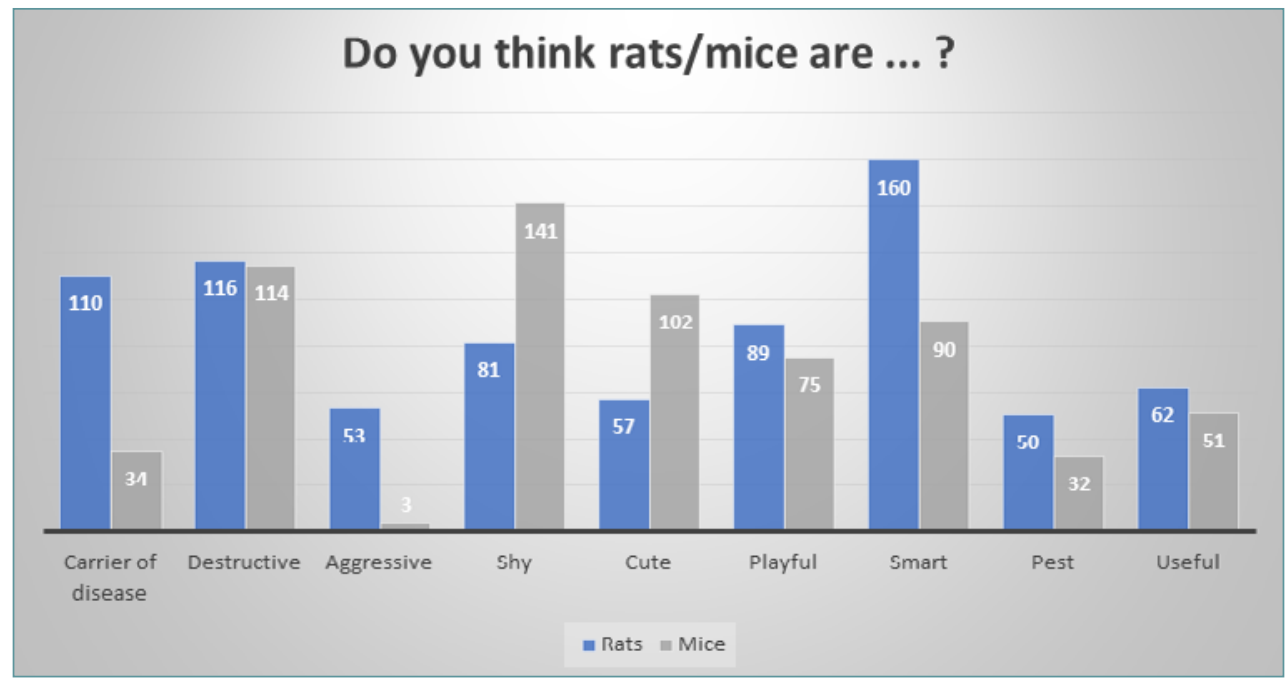

Figure 4: Behavioural traits attributed to rats and mice by participants

of diseases", "Aggressive", "Shy", "Cute" and "Smart". As the questions were asked about the negative aspects of liminal species, we assume that participants, when talking about "rats", are talking about a "symbolic rat", carrying all the most negative symbolical and emotional semiotic values participants were attributing to rodents, as Figure 3 shows that rats are more negatively seen-even if we still cannot tell for sure if participants are talking about real rats or mostly about what they believe to be a rat.

\section{NON-APPEALING SUBJECT}

The second main issue of this study was that it deals with a non-appealing subject. This leads to three consequences

First, the lack of data about real nuisances in unusual fields. One of the interviews (see "Methods" section) deals with nuisances caused by rodents from the point of view of car insurers, but this kind of data is still rare, even if the nuisances are real and expensive. Therefore, there could be more real nuisances in unexpected fields other than those introduced in this study.

Second, the subject being non-appealing leads to a small sample of participants in the survey and an even smaller one of those agreeing to be interviewed about the aspects of their jobs impacted by the species.

Third, the subject being generally non-appealing attracted a non-representative sample of the population, which is subject to what I will call here the "pet effect". There is no data on the number of domestic rat owners in France, but we estimate that around $5 \%$ of French households own at least one NAC-Nouvel Animal de Compagnie, "New Pet Species" - which include, among other species (see legal list in references), domestic rats. But in the survey, the percentage of participants currently owning or having owned a rat is $10.28 \%$. This over-representation has two consequences. The first one is that our sample has a less negative opinion of this species than is the general representation-for more details about this aspect, see the differences between 
owners and non-owners in the "Outcomes" section. The second one is that I had to detail the age repartition of owners (25-40 year olds: 81.82\%; 40-65 year olds: $13.64 \%$; $18-25$ year olds: $4.54 \%$ ) in order to reveal another effect that I will call "the Ratatouille effect" - see "Outcomes" section-that affects the 18-25 years olds but would have been difficult to see using only the raw data.

\section{OUTCOMES}

REAL NUISANCES: MATERIAL

Interviewees 1 (a pub owner), 2 (a barmaid) and 3 (a cook) all reported minor material nuisances, such as droppings, without being able to attribute them to rats or to mice for sure. All of them also reported that most of the material nuisances come from the mandatory disposal of every commodity a rodent opened or even tried to open. Rodents themselves were not reported to be eating/stealing a lot of food or spoiling many packages. None of the interviewees had ever had a bad evaluation from veterinary services. None of the interviewees reported any disease-regarding themselves, an employee or a colleague, or a client-that could be linked to the presence of rodents, such as leptospirosis.

Interviewee 1 reported a unique case of major nuisance, when an unidentified rodent gnawed power cables of a fridge, which led to a mandatory disposal of all commodities and a purchase of a new fridge.

Interviewee 4 (a car insurance employee) reported many cases of major material nuisances, which was interesting as this field is the least expected to be affected by rodents amongst those interviewed. This interviewee explained that changes in European law forced car builders to change components of engine cable sheaths from plastic to bioplastic, mostly made of corn. The smell seems to attract rodents, which gnaw and destroy cables-and consequently the car engine. These destructions did not lead to life-threatening incidents, as cars simply cannot start with this kind of damage, therefore no road accident can occur from that. But the interviewee said that this kind of damage leads to a complete destruction of the engine, a claim that can easily cost from $4.000 €$ to $8.000 €-$ it is important to specify that the interviewee's company mostly insures professionals and therefore deals with utility vehicles, which can influence the cost of an engine-and can occur up to ten times per year for owners of a very large car fleet parked in an infested area. I would like to point out the fact that the interviewee was using the word "rats" during the entirety of the interview to talk about rodents causing this kind of damage, but the size of the pipes leading to the engine is quite small, and it is more probable that only mice-or young rats-can enter and find the cables.

\section{REAL NUISANCES VS ASSUMED \\ NUISANCES: PSYCHOLOGICAL}

These first results seem to contradict the nuisances assumed by the participants. Figure 5 shows in which sectors they assumed that rodents cause the most nuisances, and we can see that the car sector is clearly low in assumed nuisances, even if interviewee 4 clearly explains that damages in this sector were frequent and expensive. On the contrary, all sectors related to food are very high in assumed nuisances, even if the interviewees from these sectors reported mostly minor nuisances.

But there is one real nuisance that participants may have perceived here, and which is supported by interviewees 1 and 2: the psychological nuisance, and more precisely the impact the presence of a rat or a mouse can have on customers. These two interviewees explained that, more than the minor material damages, they fear the reaction of a client seeing a rodent in their pub/bar. From this point of view, it is interesting to mention that participants fear a species because they fear the fear it causes to other people, not because of the species per se.

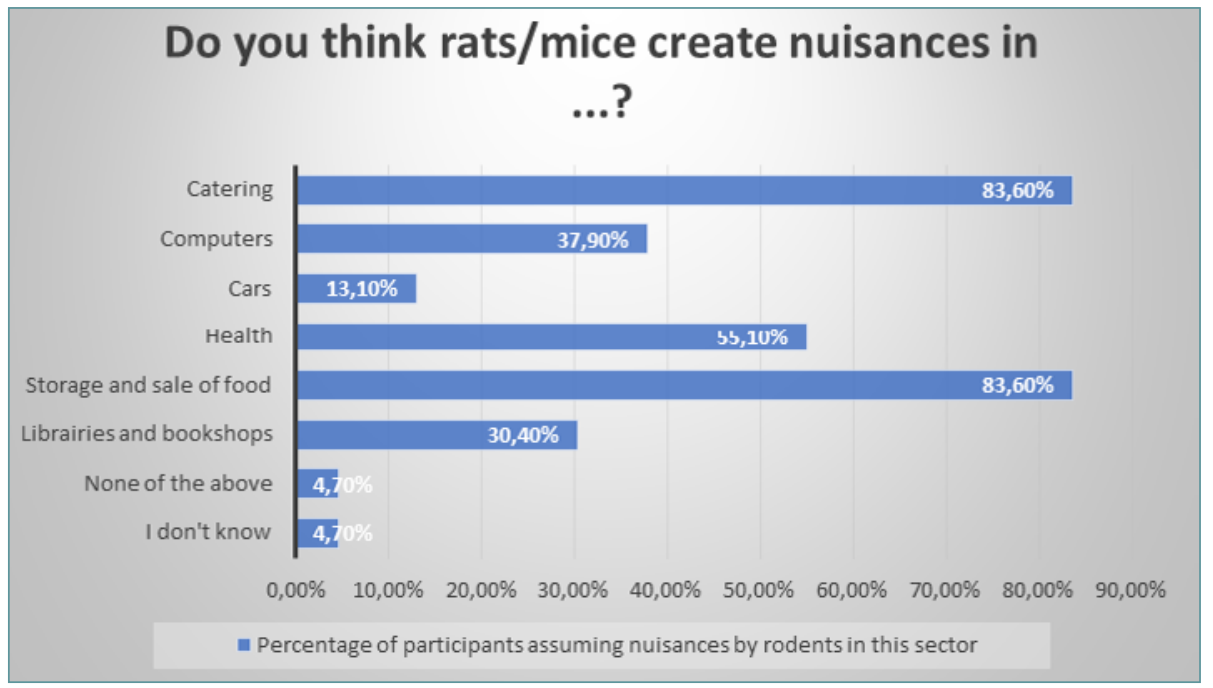

Figure 5: Fields affected by rodent nuisances according to participants 


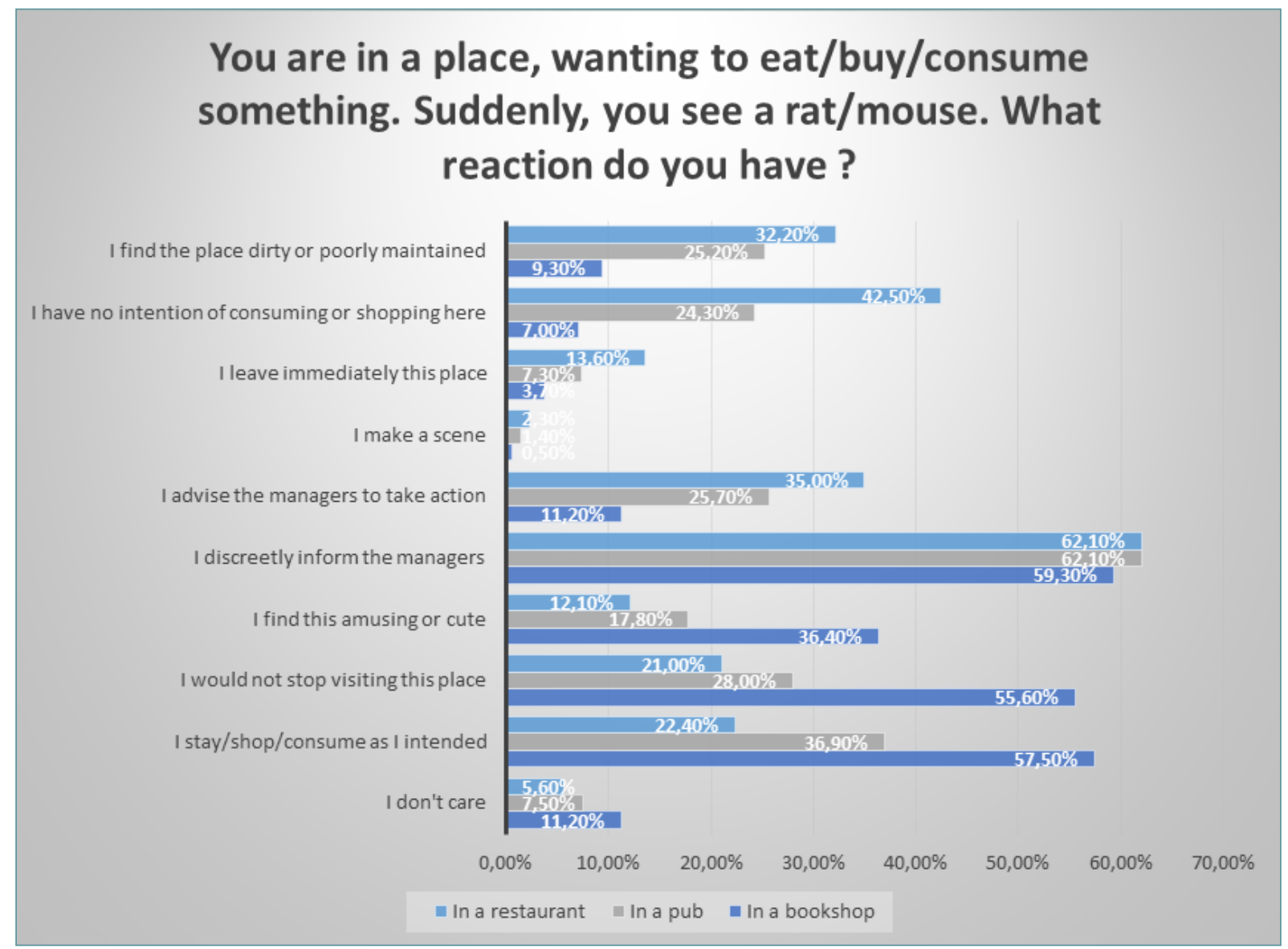

Figure 6: Reactions of participants seeing a rodent, depending on the context.

\section{PERCEIVED NUISANCES: AWARENESS OF THE} PSYCHOLOGICAL NUISANCES AND PARADOX

The participants are clearly aware of this situation. They were proposed three scenarios, in which they are intending to buy/consume something and suddenly see a rat/ mouse. The variable in the scenarios was the nature of the place. Figure 6 shows that the most constant reaction in the proposed scenarios is to discretely inform the owners of the place without alarming other customers. This reaction shows that participants are aware, at the same time, of the risk of a bad reaction from a clientthey are doing it discretely-and of the necessity that the owners have to do something about the presence of these species. Only a very small part of participants is willing to take public actions, such as making a scene.

But we can also see a paradox here. The presence of a rodent somewhere food is made or sold is easy to explain and quite expected. Its presence in a non-food-related shop, like a bookshop, is harder to explain; we can assume that the place is more infested, poorly handling its garbage or other explanations directly linked to a poor care of the place. But the reactions of participants show the contrary: when it comes to the presence of rodents, a larger number of participants considers a restaurant to be dirtier than a bookshop -even if rodents' presence is better explicable and more expected there. If other reactions can be explained by the differences in consequences (you can fear food poisoning and leave a restaurant but think you do not risk anything and stay in a bookshop), this perception of dirtiness is a paradox, and an excellent example of symbolical as well as emotional perception. The rat is a symbol of dirtiness, and the more a place makes you feel vulnerable-a place where you are ingesting food-the more this symbolic aspect interacts with participants' emotions and influences their perception.

\section{EMOTIONAL PERCEPTION AND SYMBOLICAL PERCEPTION}

Participants can be aware of a gap between their own emotions and what they believe about a species-their symbolical perception. This can be seen in Figure 7, where almost a quarter of participants shows contradiction between their symbolic perception (the belief that a species is useful or a pest) and their emotional perception-what they would like to see happen to a species.

\section{THE "PET EFFECT"}

All these results must be interpreted under the light of an effect that appears in the data, which I called the "pet effect". This psychologic and semiotic phenomenon, affecting $10.28 \%$ of the sample, is the fact that owning or having owned a rat positively influences the symbolical and emotional perceptions the participants can have. 


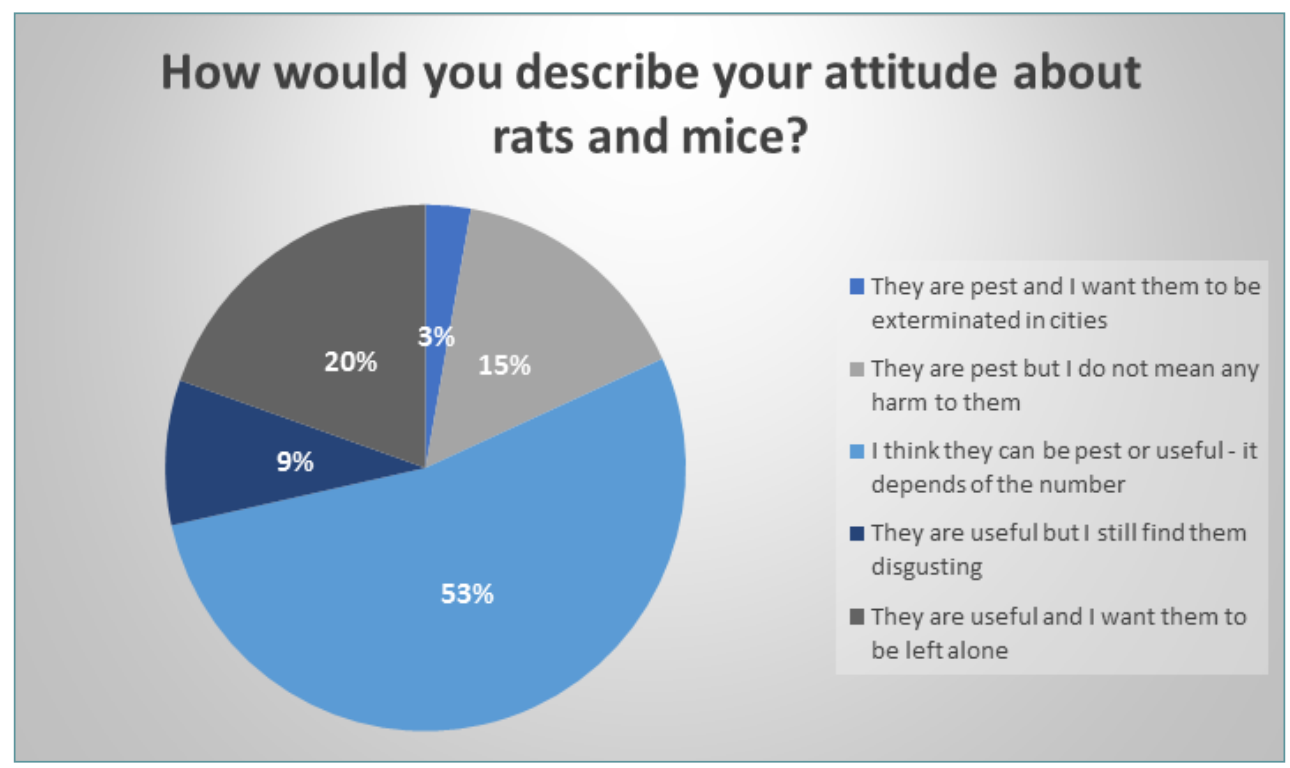

Figure 7: Emotional versus symbolical state of mind of participants

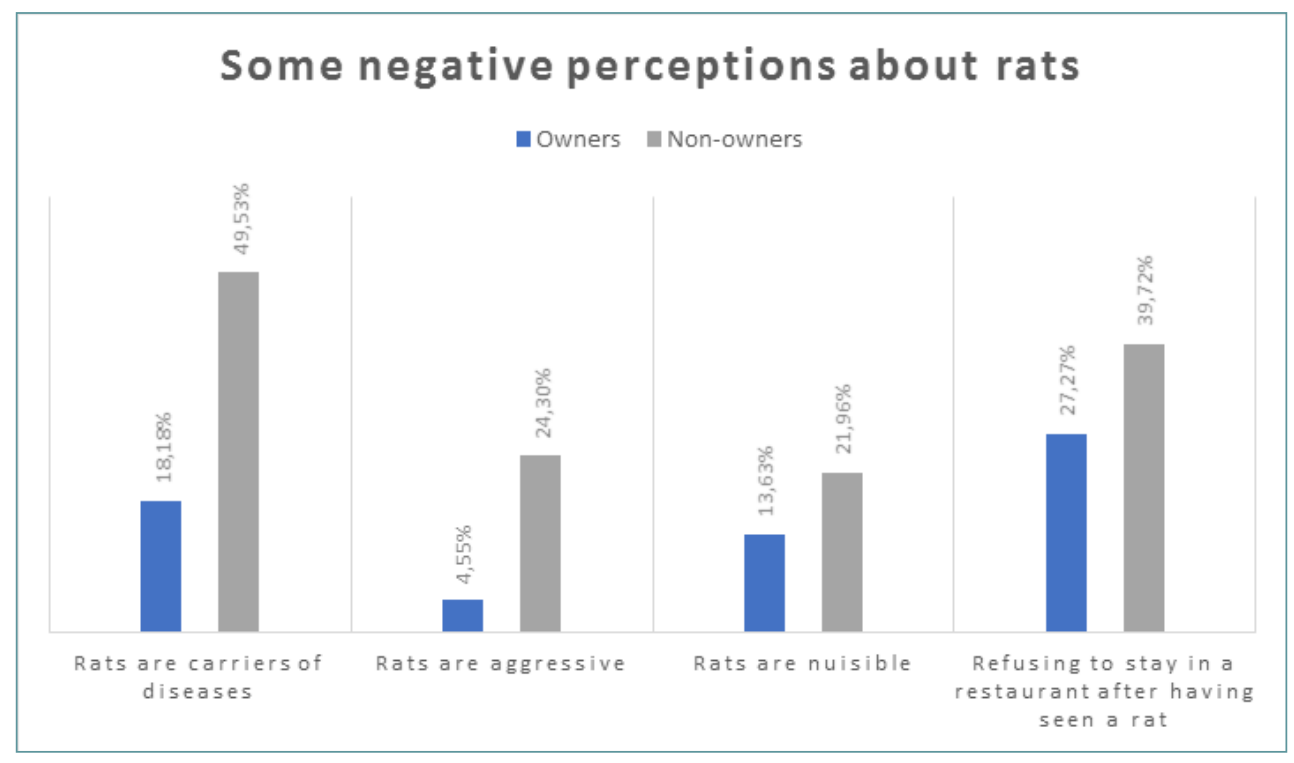

Figure 8: Difference of perception between owners-or ex-owners-of rats and non-owners

Here is a comparison between owners (or ex-owners) and non-owners for a few items from our sample.

It is important to note this effect in order to interpret the previous results as "optimistic results", as the pet effect influences positively the semiosis of a population that is over-represented in this sample. It is also important to note that this effect mainly occurs in the age group of 25-40. Not taking this into account can lead to underestimating another very interesting effect.

\section{THE RATATOUILLE EFFECT}

This effect occurs in the age group of 18-25. This age group presents quite abnormal results for all its semiosis regarding the studied species when compared to the rest of the sample-especially when the pet effect is taken into account. Indeed, this age group seems to present a more positive perception of the rat, even if no participant except one of this age group is subject to the pet effect. In the following figure, participants subject to the pet effect were excluded.

If the pet effect is already excluded, how can we explain these differences - I chose here only a few items, but the same pattern is present everywhere, being stronger when questions imply an important emotional aspect, and less visible when the question is more neutral. The hypothesis I propose here is that we are witnessing what I call "the Ratatouille effect".

The age group of 18-25 has a cultural particularity: these participants were between six and thirteen years old when the animated movie Ratatouille came out. This film features a rat in Paris dreaming of becoming 


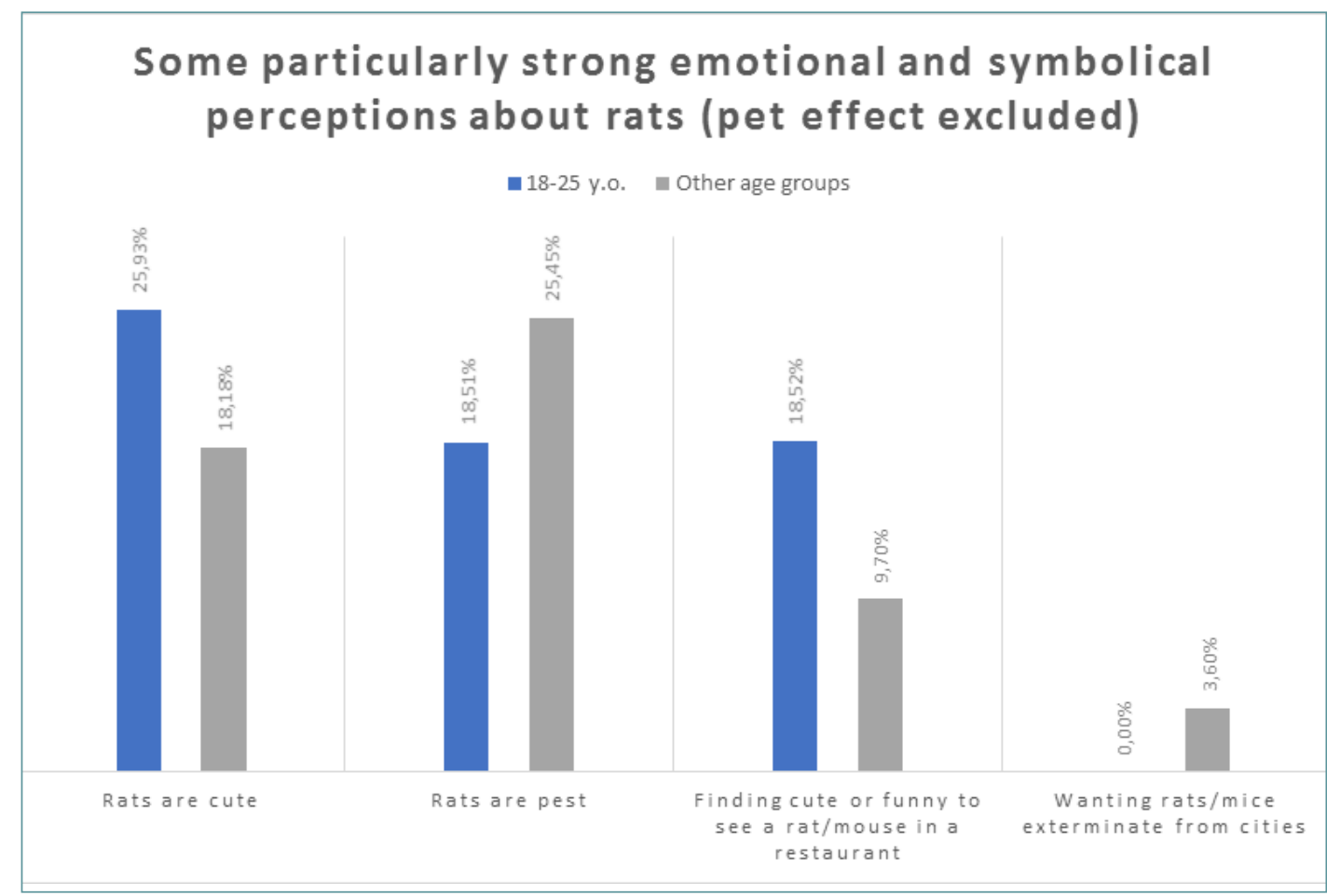

Figure 9-Difference of perception between the 18-25 year olds and other age groups, after exclusion of the individuals subject to pet effect.

a chef-and most of the movie takes place in various kitchens. This age group was, in consequence, massively ${ }^{3}$ exposed to the positive image of a cute and nice rat in a kitchen, with people helping him cook being seen as "nice" and people trying to expel him from the kitchen being seen as "bad guys".

This created semiotic patterns in those individuals whose symbolical and emotional repository was still being constructed. Such patterns were different from the ones the other age group could have and led to a variation in emotional and symbolical perception large enough to be measured.

It is interesting to note that this effect-caused by a 2007 movie-is lasting in time and seems to be able to contradict more ancient symbolical material, such as the collective memory of the plague, probably due to the early exposure of these participants to emotionally strong content.

\section{FURTHER RESEARCH}

\section{METACOGNITION}

As shown in Issues of the Study, differences between rats and mice are important from an emotional point of view as well as from a symbolic one. Therefore, evaluation of the participants' real capacity and their perceived capacity to tell the difference between these two species at sight will allow more precision in current data. This is especially true for the symbolical aspect, as it is completely possible that the participants may attribute negative traits to a "symbolic rat" but would not be so negative in front of a real specimen they mistake for a mouse.

This part of the study, scheduled but delayed, should be launched as soon as possible.

\section{MORE DATA FROM UNUSUAL SECTORS}

One interview showed that most of the material and expensive nuisances seem to occur in quite unusual sectors, or at least sectors which are not the ones commonly imagined by the participants. Further investigation should be done in order to reveal other sectors that can be impacted without our knowledge.

\section{LINK BETWEEN POP CULTURE AND SYMBOLICAL PERCEPTION}

If the link between pop culture and behaviour around animals is documented, it is mostly the phenomenon of acquiring pets represented in a film or a serial-"Nemo effect" for the clown fish, "Game of Thrones effect" for huskies, another phenomenon called "Ratatouille effect" for the domestic rat-which does not last over time ${ }^{4}$.

3 The film gathered almost 8 million tickets at the box office in France, being the third major success of Pixar, and the best debut ever in France for an animated movie.

4 Which is, precisely, a part of the problem. Brief infatuation for living beings, sometimes with a life expectancy of several decades, often leads to poor care by neophytes and abandonment when the fashion fades. 
But in our study, the effect on symbolical perception lasted for years. To strengthen the link between our data and their explanation through pop culture influence, it would be good to find other examples of links between a pop culture product and a long-term symbolical perception change in a precise age group. Some studies of this kind already exist (Berland 2019; Courchamp 2018), but they are mostly centred on more charismatic species, even if in reality they are dangerous, generating a mix of fear and fascination. The lack of studies on poorly-considered animals, and how they can go from provoking disgust to being empathetic through a change in pop culture, is still to be addressed.

\section{REFERENCES}

Arrêté du 11 août 2006-JORF, 233, NOR: DEVN0650509A, available at: <https://www.legifrance.gouv.fr/jorf/id/ JORFTEXT000000789087>

Berland, J., 2019. Virtual Menageries - Animals as Mediators in Network Cultures. Cambridge, MIT Press.

Courchamp, F. et al., 2018. The paradoxical extinction of the most charismatic animals. PLoS Biol, 16(4): e2003997.
Donaldson, S., Kymlicka, W., 2011. Zoopolis: A Political Theory of Animal Rights. Oxford, Oxford University Press.

Groves, R. M. et al., 2009. An Introduction to Survey Methodology. In Groves, R. M. et al., Survey Methodology, 2nd Edition. Hoboken, John Wiley \& Sons Publication.

Météo France Archives, available at: <http://vigilance-public.meteo. $\mathrm{fr} />$.

Sciences et Avenir, Interview of Benoît Pisanu (12/06/2018), available at: <https://www.sciencesetavenir.fr/animaux/paris-le-maire-du-17e-arrondissement-veut-faire-chasser-les-rats-par-les-internautes_124897> (Last consultation 09/03/2021).

The Telegraph video archive, Rats take over the streets of Paris as River Seine swells. Available at: <https:// www.youtube.com/watch?v=D9McamRfjAY> (Last consultation 09/03/2021). 